\title{
Effect of early cardiac rehabilitation in patients included in the Infarction Code strategy
}

\author{
Samuel Justiniano-Cordero, ${ }^{1}$ Adrián Tenorio-Terrones, ${ }^{2}$ Gabriela Borrayo-Sánchez, ${ }^{2}$ Raúl Cantero-Colín, ${ }^{2}$ \\ Verónica López-Roldán, ${ }^{3}$ Luis Rafael López-Ocaña ${ }^{4}$ and José de Jesús Arriaga-Dávila ${ }^{5}$ \\ ${ }^{1}$ National Program for Cardiac Rehabilitation and Prevention; ${ }^{2}$ Centro Médico Nacional Siglo XXI, Cardiology Hospital; ${ }^{3}$ Division of Rehabilitation \\ Units; ${ }^{4}$ Secondary Level Comprehensive Care Coordination; ${ }^{5}$ Medical Benefits Head Office. Instituto Mexicano del Seguro Social, Ciudad de México, \\ Mexico
}

\begin{abstract}
Introduction: Early cardiac rehabilitation (ECR) implemented in the Infarction Code (IC) protocol is a strategy in the care of acute myocardial infarction. The purpose of this study was to identify the effect of ECR in IC-included patients. Method: Case-control study. Consecutive patients diagnosed with acute myocardial infarction and admitted to a cardiology hospital between February 2015 and June 2017 were included. Two groups were created: I and II, before and after IC and ECR. Results: We included 1141 patients, 220 in group I and 921 in group II, with an age of $62.64 \pm 10.53$ years; $80.9 \%$ were males and $19.1 \%$ females. The main risk factors for groups I and II were sedentariness, $92.7 \%$ versus $77.8 \%$; dyslipidemia, $80.9 \%$ versus $55.8 \%$; hypertension, $63.2 \%$ versus $62 \%$; smoking, $66.8 \%$ versus $59.2 \%$; and diabetes, $54.5 \%$ versus $59.1 \%$. Rehabilitation was started earlier (1.8 \pm 1.6 versus $4.2 \pm 3.2)$ and the days spent in intensive therapy and hospitalization were fewer in group II (2.4 \pm 2.2 versus $4.8 \pm 4.1$ and $8.6 \pm 5.2$ versus $12.3 \pm 7.7, p<0.0001$, respectively), as well as the days of disability (58.6 versus 67.7). Conclusions: IC and ECR are complementary strategies that allow an early discharge from intensive therapy and hospitalization, as well as better quality of life and fewer days of disability leave.
\end{abstract}

KEY WORDS: Early cardiac rehabilitation. Infarction code. Quality of life.

\section{Introduction}

In Mexico, cardiovascular diseases are the leading cause of death and one of the main causes of morbidity. They increasingly affect men and women of productive age, causing absenteeism, disability and occupational pension. In Mexico, the National Institute of Statistics and Geography reported 685,766 total deaths from all causes in 2016, out of which approximately 97,743 were due to ischemic heart disease..$^{1-3}$ In the National Registry of Acute Coronary Syndrome (RENASCA - Registro Nacional de Síndrome Coronario Agudo) of the Mexican Institute Social Security (IMSS - Instituto Mexicano del Seguro Social), the cost for ST-segment elevation acute myocardial infarction with (STE-AMI) initial treatment was calculated to be approximately 260,284 Mexican pesos, without considering long-term costs. Several studies have shown that cardiac rehabilitation prevents the development and progression of heart disease. ${ }^{4}$

Timely diagnosis and treatment in ischemic heart disease are fundamental and affect its evolution, complications and short and long-term prognosis. It is essential to properly treat the patient during the socalled "golden hour" in order to reduce mortality and preserve the cardiac function: in patients treated at between zero and six hours there were 30/1000 deaths recorded in comparison with 20/1000 in those treated at between seven and 12 hours; the differences were recorded especially in the first two hours..$^{5-8}$
Date of reception: 19-10-2018

Date of acceptance: 16-11-2018

DOI: 10.24875/GMM.M19000238
Gac Med Mex. 2019;155:44-49

Contents available at PubMed www.gacetamedicademexico.com 
The IMSS emergency care protocol known as Infarction Code allowed to improve the reperfusion strategies and attention times in the Cardiology Hospital of the National Medical Center Siglo XXI, as well as in nine hospitals and two family medicine units, with an effective interdisciplinary communication and offering 24-hour service seven days a week; with this program, fewer early complications and deaths were reported. ${ }^{9}$

Forty years ago, patients with STE-AMI were candidates for a pension and physical activity was not prescribed. Currently, cardiac rehabilitation programs require a multidisciplinary team consisted of doctors, physiotherapists, nutritionists, psychologists and nurses, among other professionals. ${ }^{10}$ The purpose of regular cardiac rehabilitation is to avoid the prolonged rest syndrome and to initiate physical activity after a cardiovascular event, to control of cardiovascular risk factors, and to address psychological aspects, as well as to reintegrate the patient to his/her social and working life..$^{11-13}$

The expenditure disbursed by the IMSS for the item "diseases and maternity insurance" was 329,264 million pesos in 2017. Since 2010, cardiovascular and circulatory diseases are the leading cause of years of healthy life lost due to premature death and disability. They are also the main reason for outpatient visits and, in 2010, they were fourth place in emergency department visits. ${ }^{14}$ For this reason, cardiac rehabilitation programs have been developed, mainly aimed at primary and secondary prevention, with functional and symptomatic benefits for the patient. In Mexico, the number of centers with cardiac rehabilitation programs is reduced (less than $4.4 \%$ ) and they are only assigned $6.2 \%$ of the gross domestic product in comparison with an average of $9.3 \%$ in the world, as recorded by the Organization for Economic Cooperation and Development. ${ }^{15}$

Since 40 years ago, the Cardiology Hospital of IMSS National Medical Center Siglo XXI, has the Cardiac Rehabilitation Department, whose referral percentage is $15 \%$. Currently, cardiac rehabilitation has to start since the early hospitalization phase and continue after discharge with a program of physical exercise, risk factor control and education regarding the disease, guided by a multidisciplinary team. The proposal of our group is early cardiac rehabilitation (ECR), which requires enrollment and cardiac rehabilitation initiation since phase I first 24 hours, with follow-up from intensive coronary care unit (ICCU) admission and during two phases of outpatient cardiac rehabilitation and self-help. The Infarction Code protocol and ECR are part of the A Todo Corazón IMSS program for the prevention and care of cardiovascular diseases. The purpose of this work is to identify the effect of ECR in patients included in the Infarction Code, with the results compared with those obtained in patients not included in the program, in whom regular cardiac rehabilitation was provided.

\section{Method}

Through a case-control study, patients of either gender, between 20 and 95 years of age, with ejection fraction higher than $20 \%$, who were admitted to the Cardiology Hospital of the National Medical Center Siglo XXI, Mexico City, with a STE-AMI diagnosis according to the American College of Cardiology, American Heart Association and European Society of Cardiology criteria were included. ${ }^{16}$ Group I comprised patients diagnosed with STE-AMI and treated before February 2015, prior to Infarction Code implementation, and included in the regular cardiac rehabilitation program. Group II included patients diagnosed with STE-AMI in whom the Infarction Code protocol was followed and ECR was implemented. Patients with acute coronary syndrome without ST-segment elevation, severe aortic stenosis, heart failure, unstable angina, dissecting aneurysm of the aorta, uncontrolled ventricular arrhythmias, systemic or pulmonary embolism and acute infectious diseases were excluded. All patients signed an informed consent to participate in cardiac rehabilitation and in the study.

A recruitment sheet was used to analyze the data obtained from medical records. ECR includes three phases:

- Phase I, starting at between 24 to 48 hours in the ICCU. Mobilizations and stretches were performed, as well as ambulation during hospitalization (functional capacity, 1 to 3.5 metabolic equivalents [METs]).

- Phase II, after hospital discharge; it includes evaluation, stratification, physical exercise prescription, education for risk factors modification and reintegration to work activities (functional capacity, 3.5 to $10 \mathrm{METs}$ ).

Phase III, extra-institutional group physical activity (functional capacity, > 10 METs).

The dependent variables were intensive care unit days of stay, total hospitalization days, days of temporary disability and quality of life as determined by the Velasco Del Barrio questionnaire for patients with ischemic pathology and validated into Spanish, which 
consists of 40 items grouped in nine areas: health, sleep/rest, emotional behavior, future projects, mobility, social relations, alertness behavior, communication and leisure/work. ${ }^{17,18}$

Quantitative variables statistical analysis was carried out by obtaining central tendency and dispersion measures. Student's t-test was used for inferential statistics, and for qualitative variables, the chi-square test. A p-value $<0.05$ was regarded as a significant difference. The SPSS statistical program, version 24 , was used.

\section{Results}

A sample of 1141 patients was studied, 220 patients in group I and 921 in group II; $80.9 \%$ were males and $19.1 \%$ females. Total enrolled patients average age was $62.6 \pm 10.5$ years. Lower infarction was recorded in $48 \%$, anterior extensive infarction in $33.3 \%$, anteroseptal in $16.8 \%$ and lateral in $2 \%$. Anthropometric characteristics such as weight, body mass index and initial and final waist circumference are shown in Table 1. Main occupations were general employee $(44 \%)$ and administrative employee (22.6\%). Risk factors between study groups were less common in group II (Table 1).

Time to cardiac rehabilitation initiation was shorter in group II ( 2.41 days, $p<0.0001)$, as well as ICCU length of stay in $(2.46$ days, $p<0.0001)$ and hospitalization time (1.21 days, $p=0.002$ ). Total hospitalization days in group II were decreased (3.64, $p<0.0001)$; we found fewer disability days in group II, 58.6 versus 67.7 days $(p<0.0001)$ (Table 2$)$. Finally, group II showed a significant improvement in quality of life deficit (Velasco Del Barrio questionnaire) ${ }^{17}$ (Figure 1).

\section{Discussion}

Early management of the patient with acute myocardial infarction, with intervention in the acute phase aimed not only at physical activity initiation but also at patient education regarding the knowledge of his/her disease and the importance of cardiovascular risk factors control, achieves faster social and occupational reintegration and reduces care and re-hospitalization costs.

Infarction Code is a recent strategy in Mexico that includes monitoring in different departments within the intra-hospital treatment process, in addition to cardiac rehabilitation techniques and early management, intended to maximize the beneficial effect of the implemented measures.
Table 1. Characteristics of the population included in early and regular cardiac rehabilitation

\begin{tabular}{|c|c|c|c|}
\hline \multirow[t]{2}{*}{ Variable } & $\begin{array}{l}\text { Group I } \\
(n=220)\end{array}$ & $\begin{array}{l}\text { Group II } \\
(\mathrm{n}=921)\end{array}$ & \multirow[t]{2}{*}{$\mathbf{p}^{*}$} \\
\hline & Mean \pm SD & Mean \pm SD & \\
\hline Age (years) & $63 \pm 10.8$ & $63 \pm 10.1$ & NS \\
\hline Initial weight (kg) & $72.4 \pm 9.7$ & $73.53 \pm 12.2$ & NS \\
\hline Final weight (kg) & $71.8 \pm 9.7$ & $72.29 \pm 11.9$ & NS \\
\hline Initial waist (cm) & $96.4 \pm 8.0$ & $96.59 \pm 11.4$ & NS \\
\hline Final waist (cm) & $95.9 \pm 9.3$ & $93.84 \pm 15.7$ & NS \\
\hline Initial BMI (kg/height in m²) & $27.1 \pm 3.2$ & $27.34 \pm 3.8$ & NS \\
\hline Final BMI (kg/height in $\mathrm{m}^{2}$ ) & $26.7 \pm 3.6$ & $26.92 \pm 3.7$ & NS \\
\hline \multirow[t]{2}{*}{$\operatorname{LVEF}(\%)$} & $46.8 \pm 9.4$ & $46.06 \pm 9.9$ & NS \\
\hline & $\%$ & $\%$ & \\
\hline Diabetes mellitus & 54.5 & 59.1 & NS \\
\hline Systemic arterial hypertension & 63.2 & 62 & NS \\
\hline Smoking & 66.8 & 59.2 & 0.031 \\
\hline Sedentariness & 92.7 & 77.8 & $<0.0001$ \\
\hline Dyslipidemia & 80.9 & 55.8 & $<0.0001$ \\
\hline Obesity & 19.1 & 27.3 & 0.011 \\
\hline Overweight & 58.6 & 47.9 & 0.025 \\
\hline Depression & 3.2 & 2.8 & NS \\
\hline \multicolumn{4}{|l|}{$\begin{array}{l}\text { Disease by number of vessels } \\
\text { lesion }\end{array}$} \\
\hline I & 69 & 47.7 & $<0.0001$ \\
\hline$\|$ & 11.5 & 23.2 & \\
\hline III & 19.5 & 29.1 & \\
\hline $\begin{array}{l}\text { Risk stratification according to } \\
\text { AACVPR } \\
\text { Low } \\
\text { Moderate } \\
\text { High }\end{array}$ & $\begin{array}{l}57.5 \\
15.1 \\
27.4\end{array}$ & $\begin{array}{l}41.3 \\
24.1 \\
34.6\end{array}$ & $<0.0001$ \\
\hline $\begin{array}{l}\text { Group I = without early cardiac rehabilitat } \\
\text { Group II = with early cardiac rehabilitation } \\
{ }^{*} \text { 'Significance by Chi-square. } \\
{ }^{*} \text { Student's t-test. } \\
\text { SD = standard deviation, BMI=body mas } \\
\text { NS = not significant, AACVPR = Americar } \\
\text { Rehabilitation. }\end{array}$ & $\begin{array}{l}\text { tion (prior to Infarct } \\
\text { ? (Infarction Code). } \\
\text { s index, LVEF = left } \\
\text { Association of Ca }\end{array}$ & ft ventricle ejection & $\begin{array}{l}\text { fraction, } \\
\text { Pulmonary }\end{array}$ \\
\hline
\end{tabular}

In the study population, the male gender was more common (in both groups) and average age was 62.9 years, similar to Borrayo et al. ${ }^{9}$ findings, who also describe a population at higher risk. When comparing the groups, weight, waist circumference and body mass index decreases were observed in group II at the end of the program, although they were minimal and non-significant. Supervision of weekly energy expenditure per patient for a significant weight decrease 
Table 2. Impact of early cardiac rehabilitation in patients with STE-AMI

\begin{tabular}{lccc}
\hline Indicators & Group I $(\mathbf{n}=\mathbf{2 2 0})$ & Group II $(\mathbf{n}=\mathbf{9 2 1})$ & $\mathbf{p}$ \\
\hline Days to start phase I & $4.2 \pm 3.2$ & $1.8 \pm 12.4 \pm 2.2 .6$ & $<0.0001^{*}$ \\
Days of ICCU stay & $4.8 \pm 4.1$ & & $<0.0001^{*}$ \\
Hospitalization days & $7.4 \pm 5.6$ & $6.2 \pm 4.3$ & $0.002^{*}$ \\
Total in-hospital days & $12.3 \pm 7.7$ & $8.6 \pm 5.2$ & $<0.0001^{*}$ \\
Days from TWD to phase II discharge & $67.7 \pm 19.1$ & $58.61 \pm 13.4$ & $<0.0001^{*}$ \\
\hline
\end{tabular}

Group I = without early cardiac rehabilitation (prior to Infarction Code).

Group II = with early cardiac rehabilitation (Infarction Code).

*Student's t-test for independent samples.

STE-AMI = ST segment elevation acute myocardial infarction, ICCU = intensive coronary care unit, TWD = temporary work disability.

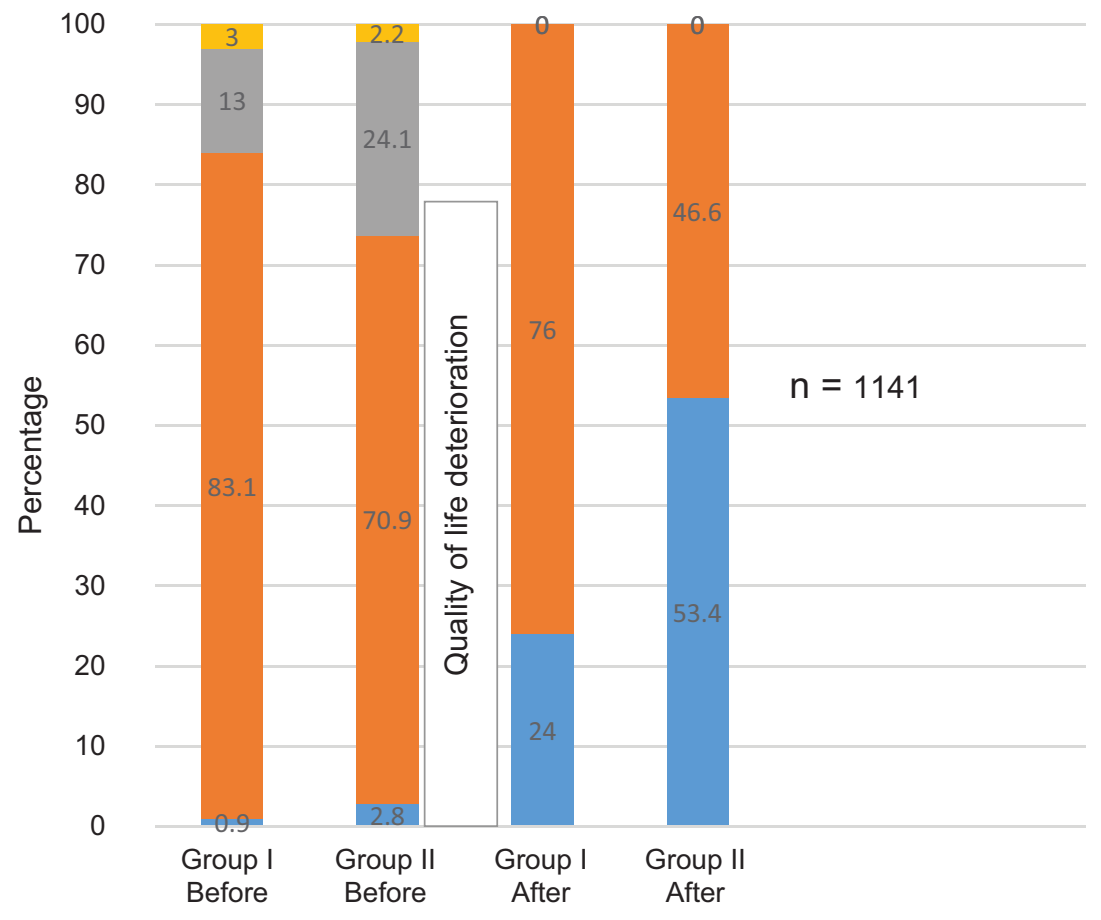

\begin{tabular}{|c|c|c|c|}
\hline Mild & Moderate & Important & Serious \\
\hline 0 a 50 & 51 a 100 & 101 A 150 & 151 a 200 \\
\hline
\end{tabular}

Figure 1. Quality of life according to the Velasco Del Barrio questionnaire. The larger percentage of patients with mild and moderate deficit in group II in comparison with group I, translates into an improvement at the end of early cardiac rehabilitation.

and hence a substantial improvement is an aspect to be improved. ${ }^{19,20}$

Given that the factors that define the evolution include the left ventricle ejection fraction and the number of affected vessels, we identified that there was a higher percentage of high and moderate risk in group II. McPhee et al., in a study of 486 patients, recorded an improvement in cardiopulmonary capacity after ECR before reaching 114 days, ${ }^{21}$ which demonstrates that offering early diagnosis, treatment and rehabilitation is crucial for a better functional prognosis. ${ }^{22}$

The Infarction Code strategy and ECR showed important benefits. ECR initiation after emergency department admission averaged 1.86 days, with a decrease of 2.4 days with regard to regular cardiac 
rehabilitation. We found a 2.4-day reduction in ICCU stay and 1.2 days in hospitalization, which suggested an early recovery and that harmful effects of immobility were avoided. ${ }^{21}$ This benefit was the result of strategies for patient enrollment and follow-up. ${ }^{23}$ In 2017, Corcoran et al. conducted a study where they determined the effects of early rehabilitation at the ICCU; as in our study, they found a significant decrease in ICCU length-of-stay, from 4.6 to 3.7 days $(p=0.05)$, as well as a $40 \%$ decrease in patients with prolonged stay of 6 to 3.4 days, an average that we observed in our research. ${ }^{24}$

As for quality of life measured with the Velasco questionnaire, our results were positive, since patients in group II showed a quality of life improvement, reflected by a higher percentage of patients with mild deficit. Anchah et al. conducted a quality of life evaluation study in patients with acute coronary syndrome on cardiac rehabilitation early phase I, where they used the SF-36 questionnaire in a six to 12-month follow-up; they found an improvement in those treated early. Our results are the consequence of various timely medical care programs, education programs and supervised physical training. ${ }^{25}$

In addition, in our analysis we show that the combined use of Infarction Code and ECR decreased disability by 9.1 days. If this figure is extrapolated to the expenditure on different resources per day of health care at the ICCU and hospitalization in secondary and tertiary care IMSS settings, possible savings per hospitalization day for the year 2016 might have been 6958 Mexican pesos. ${ }^{26,27}$ In 1993, Oldridge corroborated the cost-effectiveness benefits of cardiac rehabilitation programs; subsequently, Edwards et al., in a cost-effectiveness meta-analysis in cardiac rehabilitation, which encompassed the 2000 to 2014 period, indicated a similar average age and gender distribution. In our study, the lowest age at presentation was 22 years, which made the control of cardiovascular risk factors indispensable. ${ }^{28}$ Corcoran et al. also noted that there are significant savings when early rehabilitation is carried out; they indicated a net saving of 1.5 million dollars. ${ }^{24}$

In our study, we obtained positive results according to the reference to cardiac rehabilitation phase II; previously, the Cardiology Hospital had $15 \%$ of references and, currently, it has $89 \%$ with the seven axes of IMSS $A$ todo corazón program implementation, which includes Infarction Code and ECR; however, increasing this rates of reference is still necessary in the different centers where ischemic heart disease is treated in order to obtain substantial benefits from ECR. Among the various factors involved in the reference to cardiac rehabilitation, Goel et al. point at the role of the clinical cardiologist or attending physician; similarly, they point at the increase in references to cardiac rehabilitation over the past 10 years. ${ }^{22}$

The limitations of our study included the reduced number of control patients and the respective follow-up of the population, which are aspects that should be improved in future research and in the corresponding evaluation of cardiovascular risk decrease.

\section{Conclusions}

We identified a favorable effect of ECR implementation in patients with acute myocardial infarction included in the Infarction Code program.

Resulting from a set of actions for improvement in timely diagnosis and treatment and early rehabilitation, better enrollment and adherence to the program in phase I was obtained, with a significant reduction in ICCU days of stay, hospitalization and disability and quality of life improvement. These results indicate better quality in the care of patients with acute myocardial infarction, and a replicable ECR model is therefore suggested in all units using the Infarction Code strategy.

\section{References}

1. Plan Nacional de Desarrollo 2013-2018. México: Diario Oficial de la Federación 2013 May 20.

2. Gutiérrez JP, Rivera-Dommarco J, Shamah-Levy T, Villalpando-Hernández S, Franco A, Cuevas-Nasu L, et al. Encuesta Nacional de Salud y Nutrición 2012. México: Instituto Nacional de Salud Pública; Secretaría de Salud; 2012.

3. Instituto Nacional de Estadística, Geografía e Informática. [Sitio web]. Mortalidad 2016. México: INEGl; 2016. Disponible en: https://www.inegi. org.mx/programas/mortalidad

4. Borrayo-Sánchez G, Madrid-Miller A, Arriaga-Nava R, Ramos-Corrales MA, García-Aguilar J, Almeida-Gutiérrez E. Riesgo estratificado de los síndromes coronarios agudos. Resultados del primer RENASCA-IMSS. Rev Med Inst Mex Seguro Soc. 2010;48:259-264.

5. Chiu S, Lupercio K, Nava JR. Manual de conducta y terapéutica cardiovascular. México: Manual Moderno; 2014.

6. O'Gara PT, Kushner FG, Ascheim DD, Casey DE, Chung MK, De Lemos JA, et al. 2013 ACCF/AHA guideline for the management of ST-elevation myocardial infarction: a report of the American College of Cardiology Foundation/American Heart Association Task Force on Practice Guidelines. Circulation. 2013;127:e362-e425.

7. Steg PG, James SK, Atar D, Badano LP, Blömstrom-Lundqvist C, Borger MA, et al. ESC Guidelines for the management of acute myocardial infarction in patients presenting with ST-segment elevation. Eur Heart J. 2012;33:2569-2619.

8. Larios, R. Factores de riesgos asociados con infarto agudo al miocardio en derechohabientes atendidos en el H.G.R. No.1 Vicente Guerrero, Acapulco, Guerrero. [Tesis de especialidad]. México: Instituto Politécnico Nacional; 2011.

9. Borrayo-Sánchez G, Álvarez-Covarrubias H, Pérez-Rodríguez G, Arizmendi-Uribe E, Ramírez-Arias E, Peralta-Rosas M, et al. Impacto en la implementación de Código Infarto en pacientes con infarto agudo de miocardio con elevación del segmento ST en el Hospital de Cardiología en el Centro Médico Nacional Siglo XXI. Gac Med Mex. 2017;153:S13-S17. 
10. Martínez-Sánchez $\mathrm{C}$, Arias M, González H. Síndromes isquémicos coronarios agudos. México: Intersistemas; 2010.

11. Brown RA. Rehabilitation of patients with cardiovascular diseases. Report of a WHO Expert Committee. World Health Organ Tech Rep Ser. 1964;270:3-46.

12. Ilarraza-Lomelí $\mathrm{H}$, García-Saldivia M, Rojano-Castillo J, Justiniano S, Cerón N, Aranda-Ayala Z, et al. National Registry of Cardiac Rehabilitation Programs in Mexico II (RENAPREC II). Arch Cardiol Mex. 2017;87:270-277.

13. Cortés-Bergoderi $M$, López-Jíménez $F$, Herdy $A H$, Zeballos $C$, Anchique C, Santibáñez C, et al. Availability and characteristics of cardiovascular rehabilitation programs in South America. J Cardiopulm Rehabil Prev. 2013;33:33-34.

14. Informe al Ejecutivo Federal y al Congreso de la Unión sobre la situación financiera y los riesgos del Instituto Mexicano del Seguro Social 20162017. México: Instituto Mexicano del Seguro Social; 2018.

15. Organización para la Cooperación y Desarrollo Económico. [Sitio web]. Indicators 2014. OECD.

16. Ibáñez B, James $S$, Agewall $S$, Antunes MJ, Bucciarelli-Ducci $C$ Bueno H, et al. Guía ESC 2017 sobre el tratamiento del infarto agudo de miocardio en pacientes con elevación del segmento ST. Rev Esp Cardiol. 2017;70:1082.e1-e61.

17. Velasco J, Del Barrio V, Mestre MV, Penas C, Ridocci F. Validación de un nuevo cuestionario para evaluar la calidad de vida en pacientes posinfarto. Rev Esp Cardiol. 1993;46:552-558.

18. Soto M, Failde I. Health-related quality of life as an outcome measure in patients with ischemic cardiopathy. Rev Soc Esp Dolor. 2004;11:505-514.

19. Squires R, Kaminsky L, Porcari J, Ruff J, Savage P, Williams M. Progression of exercise training in early outpatient cardiac rehabilitation: an official statement from the American Association of Cardiovascular And Pulmonary Rehabilitation. J Cardiopulm Rehabil Prev. 2018;38: 139-146.
20. Hansen D, Niebauer J, Cornelissen V, Barna O, Neunhäuserer D, Stettler $\mathrm{C}$, et al. Exercise prescription in patients with different combinations of cardiovascular disease risk factors: a consensus statement from the EXPERT Working Group. Sports Med. 2018;48:1781-1797.

21. McPhee PG, Winegard KJ, McDonald MJ, McKelvie RS, Millar P. Importance of early cardiac rehabilitation on changes in exercise capacity: a retrospective pilot study. Appl Physiol Nutr Metab. 2015;40:1314-1317.

22. Goel K, Lennon R, Tilbury R, Squires R, Thomas R. Impact of cardiac rehabilitation on mortality and cardiovascular events after percutaneous coronary intervention in the community. Circulation 2011;123:2344-2352.

23. Oldridge N, Furlong W, Feeny D, Torrance G, Guyatt G, Crowe J, et al. Economic evaluation of cardiac rehabilitation soon after acute myocardial infarction. Am J Cardiol. 1993;72:154-161.

24. Corcoran JR, Herbsman JM, Bushnik T, Van-Lew S, Stolfi A, Parkin K, et al. Early rehabilitation in the medical and surgical intensive care units for patients with and without mechanical ventilation: an Interprofessional Performance Improvement Project. PMR. 2017;9:113-119.

25. Anchah, L, Azmi M, Slaw M, Ibrahim M, Sim K, Ong T. Health related quality of life assessment in acute coronary syndrome patients: the effectiveness of early phase I cardiac rehabilitation. Health Qual Life Outcomes. 2017;15:10.

26. Acuerdo ACDO. AS3.HCT.270116/8.P.DF dictado por el H. Consejo Técnico en la sesión ordinaria celebrada el día 27 de enero de dos mil dieciséis, relativo a la aprobación de los costos unitarios por Nivel de Atención Médica para el ejercicio fiscal. México: Diario Oficial de la Federación; 2016.

27. Instituto Mexicano del Seguro Social. Información ejecutiva de la Dirección de Información en Salud. 20 principales motivos de egresos hospitalarios 2013, camas censables. México: IMSS; 2014

28. Edwards $\mathrm{K}$, Jones N, Newton J, et al. The cost-effectiveness of exercise-based cardiac rehabilitation: a systematic review of the characteristics and methodological quality of published literature. Health Econ Rev. 2017;19:37. 